\title{
La responsabilidad social pública como elemento de política de empleo
}

\author{
María Rosa Vallecillo Gámez \\ Juan Jesús Gutiérrez González
}

\section{RESUMEN}

La Responsabilidad Social de las Administraciones Públicas ha dado sus primeros pasos, pero es mucho el camino que aún tiene que recorrer para fijarse como una verdadera política de crecimiento y desarrollo territorial. Tratamos en este trabajo de analizar brevemente las posibilidades que desde las Administraciones Públicas se tienen para poner en marcha políticas de Responsabilidad Social que incidan directamente en las creación de empleo por ende en el crecimiento de la economía local. No se trata de una utopía, sino de realidades que pretenden influir en los responsables públicos para una decidida apuesta por la Responsabilidad Social como elemento de política de empleo y algo más.

PALABRAS CLAVE: Política de empleo, responsabilidad social, cláusulas sociales, administraciones públicas.

CLAVES ECONLIT: J45, J78, L30, L38, M54.

Cómo citar este artículo / How to cite this article: VALLECILLO, M.R. \& GUTIÉRREZ, J.J. (2016):

"La responsabilidad social pública como elemento de política de empleo", CIRIEC-España, Revista de Economía Pública, Social y Cooperativa, 87, 11-38.

Correspondencia: María Rosa Vallecillo Gámez, Profesora Contratada Doctora acreditada a Titular, Derecho del Trabajo y de la Seguridad Social, Universidad de Jaén, e-mail: mvgamez@ujaen.es; Juan Jesús Gutiérrez González, Doctorando en Derecho del Trabajo, Universidad de Jaén. 


\section{EXPANDED ABSTRACT}

\section{Public social responsability as a key element in employment policy}

Social Responsibility of Public Administration has taken its first steps, but there's still way to go in order to be settled as a real growth and territorial development policy.

The concept of social responsibility, that traditionally has moved to the Company the need to keep fighting against inequality, expands the scope of the public sector demand.

Under these circumstances and during the current economic crisis, adapting the model of social responsibility by these entities implies an improvement of democratic quality in the Administration, Institutions and Public Entities. This means innovation in the public sector through the use of Social Responsibility strategies contributes to social development by introducing values of transparency, political ethics, citizen participation and open government.

Beyond the statutory obligation may be established, the assumption of social responsibility by governments and public administrations would add value to their economic, social and environmental performance, contributing to their example orientation towards global sustainability.

The most effective use of the SR to the public field is articulated through the introduction of social clauses in public procurement, which produces results at macroeconomic level, not only by opening the public market or performing an activity local public private initiative, but through different forms of collaboration that can be experienced - private-public partnerships, outsourcing of certain activities and public services ... - . That question opens a significant potential for employment and insertion in the local space.

The economic actors perceive this use of social clauses very positive, but despite its recognition and implementation regulations value, has not come to have the expected results so far. To accept social clauses as an employment policy value and an economic factor of territory development, involves overcoming resistance and finding the balance between public and private interests.

Simultaneously the inclusion of socio-labour clauses in public procurement promotes the necessary developing tools to mobilize stakeholders and ensure integration processes. Here we find the main difficulties because employment policies are ended and are recurring in what refers to programs without assessment or results that prolong unemployment for those with more difficulties. 
Therefore, social clauses are used as an employment policy, constituting a complementary element of employment and integration policies with essential character that must be developed by public powers. This element is understood as a duty of those favouring the passage of an intention to a certain implementation. The difficulty is the challenge and in the results of the action.

The concept of social responsibility applied to public domain cannot be restricted to a simple assessment of compliance with the legality and in this case the legal and economic-patrimonial responsibility are required because of their actions and management models. This necessity is also applied to the field of expectations and social values which, despite not being legislated, come to express something more than a state of mind, even generating reactions of greater or lesser acceptance and even rejection of certain behaviours.

In our opinion, the SR in the public field, and also in the private field, must go beyond a simple voluntary action in order to achieve some "profit". Well understood the public content, the SR should be an essential obligation in this area and therefore become part of its management. But until this obligational perspective of public authorities is not accepted, the choice to go for is to advance in the request and in social pressure that should involve its application.

In general, the specific rules concerning social responsibility are limited and their origin is in international institutions such as the OECD and the ILO and in most cases, the wording refers to the company. Fortunately, local corporations are becoming aware of their impact and begin to worry about minimizing the adverse effects of its management to citizenship.

The development of policies that incorporate SR contributes to the systematization of policies and processes with a direct impact on the local economy and thus in employment, and also facilitates external communication, serving as criteria for decision-making and helping to define commitments, being ultimately a model of guidance for territory companies.

The policy measures of employment and social inclusion in recent years are not renewed and continue to point only to improve the "employability" and to remove certain obstacles to access the labour market by hiring incentives; but the economic growth model is not the main causative factor of exclusion. We continue having exclusive and discriminating labour markets. By applying social and labour clauses, in addition to works or services, it gets a social profitability that implies firstly a social investment and a contribution, to reduce public expenditure allocated for this purpose - basic income, unemployment benefits or health costs - and secondly generating an income to the tax offices by income tax, VAT and Social Security. The so-called "social return". 
The TRLCSP 2011 considers several possibilities to take into account social aspects in procurement. In connection with this policy, many municipalities and autonomous regions have published standards to incorporate different types of social considerations in their contracts. Also the advisory bodies and the Courts have largely ruled on the legality of different aspects of social policy in public procurement;

At EU level, Directive 2014/24 / EU of the European Parliament and of the Council of 26 February 2014 on public procurement, requires states to take effective measures to ensure the implementation of contracts compliance with the legal social commitments and conventionally established in Article 18.2. This precept regulates the basic principles of public procurement, that indicates the importance given to the subject.

In Europe, however, the use of social clauses in public procurement reached a turning point with the call Rüffert (C-346/06) the Court of Justice of the European Union (ECJ), for which the use of such clauses are in accordance with EU law only when they are supported by the European Directive on worker movements (96/71 / EC).

For all countries included in this study, Rüffert case introduces some important questions. It has get to the limit the scope and the commitment on social clauses and it has created some great legal uncertainties, particularly regarding the EU Law and ILO Convention 94.

It is therefore a subject, not only as a current subject but as an implementation responsibility by the government, which makes its study and reflection especially attractive.

Keywords: Employment policies, social responsability, social clauses, public administration. 


\section{1.- Introducción1}

El concepto de responsabilidad social que tradicionalmente ha trasladado a la empresa la necesidad de implicarse en la lucha contra las desigualdades, amplía su ámbito de exigencia al sector público, no siendo ya una función exclusiva del denominado Estado Social.

En la realidad, sobre todo en la realidad social en la que se desenvuelve la Responsabilidad Social (RS), hasta ahora ha predominado su aplicación voluntaria, progresiva y mayoritaria por organizaciones del sector privado, habiéndose extendido mucho menos, podíamos decir que escasamente, al ámbito del sector público.

Con estas circunstancias y en el actual contexto de crisis económica, la adaptación al modelo de Responsabilidad Social por parte de estas entidades, implica una mejora de la calidad democrática en la Administración, las Instituciones y las Entidades Públicas. Esto supone innovar en el sector público mediante el recurso a estrategias de Responsabilidad Social lo que contribuye al desarrollo social mediante la introducción de valores de transparencia, ética política, participación ciudadana o gobierno abierto. Y ello porque los efectos de la crisis -numerosas y sobrecogedoras reducciones de plantilla, pérdidas de beneficios sociales y sacrificios de la innovación- son consecuencia de conductas que no ayudan a fortalecer la confianza social.

La responsabilidad social ha sido objeto de un amplio debate terminológico y sigue latente la controversia de su rango como acción imperativa o voluntaria, bien porque forme parte de la obligación de la política pública o bien porque se configure como acción voluntaria en tanto que matiz innovador del sentido público de la Administración. Es recurrente estudiar y fomentar la responsabilidad social en el ámbito privado, pero a medida que se ha incrementado la concienciación social en torno a esta cuestión, han surgido voces, tanto desde el sector privado como desde el público, que reclaman un papel más activo de los gobiernos y Administraciones Públicas en la aplicación de la Responsabilidad Social, como elemento de desarrollo económico.

Más allá de la obligación normativa que pueda establecerse, la asunción de la responsabilidad social por parte de los gobiernos y Administraciones Públicas añadiría valor a su desempeño económico, social y ambiental, contribuyendo con su ejemplo a la orientación hacia la sostenibilidad global de otras entidades, tanto dentro como fuera del sector público.

1.- Este trabajo se realiza en el ámbito del proyecto de investigación SEJ-365 "Políticas de empleo, Mercado de Trabajo y Derecho a la Inserción". Universidad de Jaén. 
El uso más eficaz de aplicación de la RS al ámbito público se articula a través de la introducción de cláusulas sociales en la contratación pública, lo que produce resultados a nivel macroeconómico, no solo con la apertura del mercado público o de la realización de una actividad pública a la iniciativa privada local, sino que a través de las distintas formas de colaboración que pueden experimentarse -partenariados público-privados, externalización de determinadas actividades y servicios públicos- se abren importantes potencialidades de empleo e inserción en el espacio local. Este es el argumento central de este trabajo.

Este recurso a las cláusulas sociales se percibe como muy positivo por los actores económicos, pero, a pesar de su reconocimiento y puesta en valor normativa, no ha llegado a tener, de momento, los resultados que se les esperan. Aceptar las cláusulas sociales como un valor de política de empleo y desarrollo económico del territorio, desde el punto de vista de los actores públicos, supone vencer resistencias y encontrar el equilibrio entre los intereses públicos y los privados. Los beneficios en el conjunto del territorio pueden maximizarse con la implementación y la toma de conciencia de la inclusión de estas cláusulas como objetivo social fundamental con resultados económicos.

Al mismo tiempo que se promueve la inclusión de cláusulas socio-laborales en la contratación pública, se hace necesario desarrollar herramientas que permitan tanto movilizar a los actores implicados como asegurar los procesos de inserción. Aquí nos encontramos las principales dificultades porque las políticas de empleo están agotadas y resultan recurrentes en lo que a programas se refiere, programas que sin evaluación ni resultados, prolongan en el desempleo a quienes más dificultades tienen.

Las cláusulas sociales, por tanto, en su uso como política de empleo, constituyen un elemento complementario de las políticas de empleo e inserción que con carácter esencial han de desarrollar los poderes públicos, entendido como un deber de estos el favorecer el paso de una intención a una puesta en marcha concreta. En la dificultad está el reto, y en el reto de la acción, los resultados. Seguro que por encima de lo que se pueda intuir. 


\section{2.- La Responsabilidad social en el ámbito público}

Son cada vez mayores las limitaciones en los presupuestos del sector público y el énfasis en la eficacia y la búsqueda de la "mejor relación coste-beneficio" insta a los organismos públicos -con cierta exigencia en algunos casos- a acercarse a las formas del sector privado. Es este el proceso de transformación de la gestión pública en el que cada vez son más los valores del sector privado, su ética y estilo de gestión, que se incorporan.

Es el caso de la responsabilidad social. La concepción originaria de la responsabilidad social es la de un modelo voluntarista en el sector privado, que se extiende vagamente en los últimos tiempos al ámbito público y que se justifica en la absorción legal de principios y deberes intrínsecos al modelo de responsabilidad social (YERA, 2010).

El concepto de responsabilidad social aplicada en el ámbito público no puede restringirse a una mera valoración del cumplimiento de la legalidad y en su caso de la exigencia de responsabilidades legales y económico-patrimoniales por sus actuaciones y modelos de gestión. El "deber ser" alcanza también al ámbito de las expectativas y los valores sociales que, pese a no estar legislados, vienen a expresar algo más que un estado de opinión, generando incluso reacciones de mayor o menor aceptación y hasta de rechazo a determinadas conductas y comportamientos.

En el marco de la Responsabilidad Social Pública, la atención a las necesidades de los agentes del sector privado, entre los que se encuentran clientes, proveedores, distribuidores o trabajadores, va evolucionando al mismo tiempo que el interés por las demandas y expectativas ciudadanas. La integración voluntaria de las preocupaciones sociales y de las exigencias de los ciudadanos en las decisiones de los poderes públicos implica una aproximación al modelo socialmente responsable implementado en el sector privado a través del ajuste de la política a las demandas de la ciudadanía y un uso responsable de la política. No obstante, la voluntariedad que caracteriza a la RS y su carácter parajurídico comienza a ceder en su traslación a la esfera pública, a través de su mutación en normativa legal y exigible.

En este sentido, ante una legislación estatal excesivamente básica en lo que a esta cuestión se refiere, el ámbito local se presenta como un escenario propicio para establecer políticas y normativas con un nivel superior de compromiso hacia los ciudadanos y actuar de un modo socialmente más responsable mediante un plus respecto de las previsiones mínimas legales, especialmente en competencias como transparencia, información pública o participación, en tanto que claves asumidas del modelo de Responsabilidad Social (PINO, 2012). 
La adaptación de la Responsabilidad Social al ámbito público plantea a priori la necesidad de dirimir entre su voluntariedad y obligatoriedad, considerando que el tratamiento no puede ser idéntico en relación al sector privado y empresarial. De modo que la adopción voluntaria de estrategias socialmente responsables en la gestión empresarial no puede extrapolarse a la Administración donde el nivel de exigibilidad debiera ser superior. Asumiendo el matiz de voluntariedad, el concepto de voluntariedad de la RS más institucional sea quizá el que recoge el Libro Verde de la Comisión Europea, que lo define como "la integración voluntaria, por parte de las empresas, de las preocupaciones sociales y medioambientales en sus operaciones comerciales y sus relaciones con sus interlocutores"2.

Asumir la voluntariedad en la aplicación de la RS en el ámbito público no significa estar de acuerdo con este planteamiento. A nuestro juicio, la RS en el ámbito público -y por qué no también en el privado- ha de ir más allá de una mera acción voluntarista destinada a conseguir una "ganancia". Bien entendido el contenido de "lo público", la RS debería ser una obligación intrínseca a este ámbito y formar parte de su gestión. Pero hasta tanto se asuma esta perspectiva obligacional de los poderes públicos, no queda más alternativa que avanzar en la solicitud y la presión social que ha de implicar su aplicación.

Desde esta perspectiva, se fundamenta un enfoque neoempresarial de la Administración e Instituciones, "despolitizando" o "repolitizando" el sector público en torno a los valores y principios de un modelo social. La Ley 2/2011, de 4 de marzo, de Economía Sostenible reconoció que las Administraciones Públicas mantendrían 3 políticas de Responsabilidad Social. Sin embargo, ha sido con posterioridad en el Estado Autonómico mediante el desarrollo de los textos estatutarios, cuando se ha verificado el impulso de disposiciones - si bien escasas y con poco nivel de aplicación - con un sustrato socialmente responsable.

El papel del poder público como promotor de la RS y, en particular, de las iniciativas que la ponen en práctica es, a nuestro entender, fundamental en la incentivación del desarrollo económico local, en tanto que garante del crecimiento de los territorios. Esta promoción puede desarrollarse con diferentes fórmulas que incluirían la difusión pública, el reconocimiento directo de los esfuerzos de organizaciones individuales o partenariados 0 , el elemento que más nos interesa por considerarlo el más eficaz en la consecución de los objetivos que nos mueve impulsar, la incorporación de aspectos sociales en la contratación pública, las denominadas cláusulas sociales, recogidas expresamente en la Ley 30/2007 de Contratos del Sector Público y que permiten influir sobre el mercado y el entorno.

2.- Comisión Europea, 2001

3.- En una interpretación purista de la norma, el reconocimiento del "mantenimiento" de las políticas de RS por parte de las AAPP, podría considerarse una obligación para las mismas, en la tesis que sostenemos. 
En general, la normativa específica relativa a la responsabilidad social es escasa y está originada en instituciones internacionales tales como la OCDE y la OIT. En la mayoría de los casos, la redacción está referida a la empresa. En este sentido el concepto de responsabilidad común y compartida se traza como el punto de partida desde el cual construir el nuevo modelo de sociedad que se demanda. Cada vez es más aceptado el principio que postula la administración pública como referente de un papel crucial en la sociedad que no quede únicamente restringido a la transparencia en su actuación si no también, a la creación de riqueza y empleo. Es ya un hecho -aunque de carácter leve- que las administraciones públicas comienzan a enmarcar sus líneas estratégicas y su marco de actuación y de desarrollo en este tipo de políticas.

Afortunadamente las corporaciones locales van tomando conciencia de su impacto y comienzan a preocuparse por minimizar los efectos adversos de su gestión hacia la ciudadanía. Y puesto que no sirve solo con el compromiso interior que generan este tipo de responsabilidad, los gestores públicos deben tener en cuenta, con su actitud proactiva, los beneficios que aporta trabajar en esta dirección, no solo en lo que a imagen y confianza se refiere, sino en el impacto social y de desarrollo del territorio.

Una visión general de las corporaciones locales en España pone de manifiesto que están asumiendo, aunque solo sea de facto, el ámbito competencial más inmediato y próximo a la sociedad. Por ello cabe plantearse analizar su protagonismo esencial en el impulso de la responsabilidad corporativa, atendiendo tanto a su marco normativo, como a la percepción de los principios globales de sostenibilidad y de sus grupos de interés, y a la exigencia social de responder de sus impactos en su entorno más directo e inmediato -el local-.

El estudio de la responsabilidad territorial de los poderes públicos (García de Enterría, 2003) es asunto de interés multidisciplinar, en el que intervienen disciplinas como la Economía, pero también el Derecho (Fernández, 2008) y, no pudiendo quedarse en el ámbito teórico de las disciplinas que lo reconocen y lo impulsan es, a su vez, consecuencia de una demanda social (Heidrick y Struggles, 2009). La legítima exigencia de la sociedad de que el sector público lleve a cabo una gestión responsable, requiere que su actuación sea respetuosa e incluso ejemplar con el espíritu y letra de la ley, las costumbres y los principios y valores sociales y éticos, con el entorno socio-económico y medioambiental y la herencia cultural y política (Cueto, 2009). Y esto no ha de suponer solamente una declaración de intenciones, sino una implicación absoluta de la administración en la aplicación y resultados de la misma. Las administraciones públicas están, por tanto, llamadas y obligadas a integrar los principios de responsabilidad social en sus sistemas de gestión y en las relaciones con sus interlocutores (Rivera, 2010).

Pero el sector público tiene una naturaleza jurídica con una característica diferencial y entendemos que prioritaria, con respecto al sector privado: la aplicación del principio de autoridad para atender necesidades colectivas. Frente a la libertad del agente privado, tal y como hemos comentado con anterioridad, el actor público debe someterse al obligatorio cumplimiento de unas normas, de modo 
que se puedan presentar los beneficios económicos y sociales que propicia, frente al mero cumplimiento de obligaciones. Los fallos del mercado describen para el sector público una responsabilidad económica de primer grado y se refieren a todas las circunstancias en las que el mercado pueda no ser eficiente.

Todos estos planteamientos no han de quedarse solo en actuaciones que se deriven de una obligación social. Cada vez resulta más imprescindible que la responsabilidad social pública esté integrada como una herramienta estratégica para el desarrollo de la competitividad futura.

En cuanto a las políticas públicas, materia que nos interesa especialmente, el rol del sector público habitualmente es concebido como promotor y facilitador de las condiciones necesarias para que la responsabilidad social se transforme en un aspecto relevante en el funcionamiento de las organizaciones empresariales, así como un aspecto cultural de los habitantes de un país, estableciendo incentivos y acciones de sensibilización respecto del comportamiento socialmente responsable, así como desarrollando acciones concretas destinadas a establecer la responsabilidad social como un criterio de obligado cumplimiento por parte de los proveedores y clientes de las administraciones.

\subsection{El "nuevo" papel de la RS pública en el empleo y el Desarrollo Local}

El período actual de crisis económico-financiera está ocasionando efectos importantes en las políticas de Desarrollo Local. El intenso incremento del desempleo y el recorte en gasto social y políticas de empleo, ha supuesto un freno a estas políticas para contrarrestar los impactos de la crisis en el mercado local.

Esta situación, no obstante, puede convertirse en una ocasión propicia para buscar nuevos caminos en el funcionamiento y la gestión de estos actores e instituciones. No podemos aun hablar de un nuevo paradigma económico y social pero sí podemos hacer de la RS un instrumento, en fase de "reinvención", porque no es nuevo, que facilite la colaboración entre administraciones públicas, empresas y sociedad, para la búsqueda de alternativas para un crecimiento económico diferente al que ha provocado esta difícil situación.

A nuestro juicio lo fundamental es que la perspectiva que tome la RS deje a un lado los planteamientos pre-crisis de carácter meramente instrumental y en este modelo que propugnamos, se "reinvente" hacia otros modelos integradores o estratégicos que se conviertan en instrumentos para concertar intereses de los distintos agentes hacia un incremento de la economía local y por ende, del empleo (Heincke, 2005), adoptando el modelo de desarrollo endógeno (Estela, 2012). Esto supone favorecer un proceso reactivador de la economía local mediante el aprovechamiento de los recursos existentes y la cooperación público-privada, para estimular y fomentar el crecimiento económico del territorio, la creación de empleo, renta y riqueza con el fin último de mejorar la calidad de vida y el bienestar de las poblaciones locales. 
Este modelo de desarrollo del territorio encuentra su justificación en la evolución hacia una combinación de pseudo-descentralización, tanto funcional como administrativa, a través de la delegación y deslocalización de determinadas competencias y actuaciones, hacia el ámbito local, aunque estas no tengan un poder real de decisión. Esto ha generado una limitación a los resultados a corto plazo en el crecimiento, pero también supone un reto para las corporaciones locales en el diseño de estrategias y políticas de crecimiento económico como las que en este trabajo analizamos y potenciamos.

\subsection{Políticas de Desarrollo Local y Responsabilidad Social}

Como hemos comentado, frente a la corriente dominante liberal en la que encuentran su base las políticas europeas de austeridad y recortes contra la crisis, encontramos otra perspectiva tendente a la revitalización de la actividad económica y a la reactivación del mercado de trabajo.

No podemos obviar la situación de crisis de las haciendas locales que provocan una reducción a mínimos de las actuaciones, que inevitablemente redundan en menores niveles de cohesión social. del efecto de adelgazamiento de los erarios locales se deriva un incremento de las necesidades sociales, de manera que se hace necesario el desarrollo de un modelo que amine las secuelas de la depresión. Son las entidades locales, desde su legitimidad institucional y su proximidad al territorio y por tanto su conocimiento, las que tienen la responsabilidad sobre las actuaciones que puedan promoverse en ese ámbito para trabajar las fortalezas y oportunidades. El diseño de políticas de empleo y la búsqueda de apoyo al tejido productivo, puede ser sin duda, una buena incubadora para el fomento y la implementación de la RS de manera integrada en sus planes territoriales.

El desarrollo de políticas que incorporen la RS coadyuva a la sistematización de las políticas y procesos con un impacto directo en la economía local y por ende en el empleo, y además facilita la comunicación externa, sirve de criterio para la toma de decisiones y ayuda a definir compromisos, siendo en última instancia un modelo de orientación para las empresas de territorio. Y no es menos cierto que un modelo de RS integrador aporta experiencia al ámbito público sobre las relaciones con los stakeholders, propicia la colaboración entre las administraciones públicas y los agentes presentes en el territorio -empresariado local y entidades ciudadanas, principalmente-, redundando en la posición competitiva del propio territorio (Ancos, 2011; Díaz et al., 2011; Villasante, 2011)4.

4.- Incide también en esta teoría el grupo de trabajo 1 del CERSE en el documento: "El papel de la RSE ante la crisis económica: su contribución a un modelo productivo, la competitividad y el desarrollo sostenible". Ministerio de Trabajo e Inmigración, 2011.

http://www.mtin.es/es/sec_trabajo/autónomos/economía-

soc/RespoSocEmpresas/docs/110503_GTRUPO_DE_TRABAJO_EL_PAPEL_DE_LA_RSE_ANTE_LA_CRISIS_ECONOMICA.pdf

CIRIEC-España, Revista de Economía Pública, Social y Cooperativa

ISSN: 0213-8093

№ $87 / 2016$, pp. 11-38 
La base del establecimiento de estas políticas de desarrollo local con inclusión de la RS se encuentra en las experiencias de los planes estratégicos, las agendas locales, las prácticas de economía social, los programas de creación de empleo y la promoción del autoempleo, la introducción de cláusulas sociales en la contratación pública... todas ellas surgidas desde lo local. Por tanto, son las administraciones públicas en su papel de coordinación de los agentes locales y de intermediarias con administraciones de ámbito superior, las que pueden tener, nos atreveríamos a decir "deben tener", un importante papel en la implantación de la RS en las políticas de desarrollo local.

\section{3.- Los partenariados público-privados}

Partenariado público-privado es un término genérico que resume todas las formas de cooperación de la Administración con el sector privado para la realización, la financiación y la explotación de una obra o un servicio público, implicando una financiación privada y una ejecución también privada, supervisada por la administración pública. En él intervienen agentes 0 actores públicos y privados que Freeman (Freeman, 1984) denominó los agentes implicados -"les parties prenantes" (Jones, 1995; Donaldson y Preston, 1995; Hill y Jones, 1992; Miller-Millesen, 2003)5 o stakeholder-y los definió como un grupo $o$ un individuo que puede afectar a, o puede verse afectado por, la puesta en marcha de los objetivos de una organización.

En nuestro planteamiento no solo es muy importante, sino necesario, analizar el rol de colaboradora de la Administración en RS, pues los acuerdos estratégicos pueden agrupar y poner en común las capacidades y los logros complementarios de los sectores público y privado y de la sociedad civil a través del establecimiento de partenariados, como más adelante veremos. Las administraciones públicas adoptan distintos papeles con lo que pueden actuar como participantes, como coordinadoras o como facilitadoras de estos sistemas de gestión.

Por tanto, la Administración dispone de herramientas para impulsar directamente el proceso de implantación de la cultura de la RS, no siendo exclusivas de ninguna Administración las políticas que las apoyan y las sustentan. Es más, en la estructura territorial española son perfectamente compati-

5.- La teoría de las "parties prenantes" que podemos traducir como las partes intervinientes o actores, parte del principio de que la empresa no debe atender únicamente a los accionistas sino al conjunto de los actores con los que se relaciona. Sobre la base de un fuerte contenido normativo, esta teoría ha llegado a ser una de las piedras angulares de la responsabilidad social de las empresas y se ha reafirmado progresivamente como una corriente teórica mayor para un mejor conocimiento de la empresa y, de manera general, de la organización. La teoría de los actores está anclada en una visión económica "néo-institutional", que busca reunir a las empresas/instituciones más allá de su comportamiento maximizador del beneficio, como instituciones reformuladas sobre un conjunto de contratos. No es sorprendente, por tanto, que los autores de la teoría de las partes intervinientes utilicen un determinado número de conceptos que se han tomado prestados de la teoría neo-institucional, tales como el "nudo de contratos". 
bles las intervenciones públicas de la Administración General del Estado, de las administraciones autonómicas y de las administraciones locales. Pueden producirse incluso sinergias de interés, así determinadas políticas de fomento a la RS tienen un campo específicamente local, sobre todo en lo que a incidencia sobre el desarrollo del territorio y fomento del empleo se refiere. De hecho, son varias las razones por las que la Administración Local impulsa iniciativas de promoción de la Responsabilidad Social, entre ellas: la mayor proximidad y conocimiento del territorio, y el fin de la propia Administración Local con su papel catalizador de las voluntades de los actores del territorio, basado en una cultura de corresponsabilidad.

Podemos considerar, en atención a estos criterios, que la Administración Local es una de las más indicadas para liderar y dinamizar la implementación de los principios de la Responsabilidad Social, favoreciendo así un modelo de desarrollo territorial estratégico, permanente, innovador y de calidad, siendo fundamental además trabajar por una Administración pública más responsable socialmente, haciendo hincapié en que las medidas en materia de RS que la Administración aplicará para promover el comportamiento socialmente responsable dentro de sus propios departamentos, promoverán actuaciones ejemplares para el resto de organizaciones, empresas y ciudadanía, convirtiéndose en modelo de desarrollo.

Una de las principales cuestiones a lo largo de la historia del pensamiento económico ha sido precisamente el papel del Estado en la economía (Fernández, Peña y Hernández, 2008). Diversos autores han tratado sobre las funciones económicas del sector público, que han llegado a sintetizarse en tres: estabilidad de la economía, redistribución de la renta y asignación eficiente de recursos (Musgrave y Musgrave, 1973). En este sentido el origen de la RS está ligado tanto a la función estatal de regular el bienestar y la convivencia social, como a la función solidaria asumida por muchos empresarios y otras formas de asociación colectiva en paralelo a la construcción progresiva del Estado de bienestar. Pero en los períodos de crisis económica es cuando más se evidencia que el Estado no puede/debe cubrir todas las necesidades de sus ciudadanos (O'Connor, 1981), de ahí la necesidad del establecimiento de partenariados público-privados.

En un teórico mercado de competencia perfecta donde compitieran la iniciativa pública y la privada, si el gasto público es más eficiente que el privado crecerá la iniciativa pública, pero si ocurre lo contrario crecerán la inversión y el consumo privado. Esto se compensaría con el establecimiento de las colaboraciones entre ambos sectores. El problema es que la perfección teórica en términos de competencia no siempre se alcanza en la realidad. El sector público hoy concurre junto a otros agentes económicos en la administración de recursos escasos dentro de un contexto económico, social y ambiental cuya dimensión espacial se ha globalizado y cuyos impactos afectan a generaciones presentes y futuras, por eso es tan importante este papel de la RS pública.

Los partenariados, por tanto, permiten establecer una nueva relación entre la Administración y las empresas, para que éstas asuman su compromiso con la RS, integrando esas preocupaciones sociales en sus actividades comerciales e implicándolas en la consecución de objetivos sociales, y sobre 
todo en la creación de empleo, entendido este como el mayor instrumento de inclusión social, afectando, pues, al crecimiento económico en general y del territorio en particular, por el efecto de expansión que tiene en el espacio globalizado.

Así, la RS aporta valor a la sociedad, un valor "compartido" en el espacio de estos partenariados, en el que "la mutua dependencia entre las corporaciones y la sociedad implica que las decisiones de negocios y las políticas sociales deben seguir el principio de valor compartido. Es decir, las alternativas escogidas deben beneficiar a ambos lados. Si una empresa o una sociedad sigue políticas que benefician a un solo lado a expensas del otro, se encontrará en una senda peligrosa. La ganancia temporal de una socavará la prosperidad a largo plazo de ambas" (Porter y Kramer, 2006).

Si relacionamos el Desarrollo Local con la RS en el ámbito de la colaboración público-privada, invertimos el esfuerzo en creación de empleo, renta y riqueza con el fin de mejorar la calidad de vida y el bienestar de las poblaciones locales. Las políticas a implantar serán de generación de estrategias que ofrezcan nuevos horizontes de promoción a sus comunidades, actuaciones directas en fenómenos vinculados con la RS pública, tales como la inclusión de cláusulas sociales en los procedimientos de contratación, que deben de incluir la evaluación del impacto social y la devolución al territorio, y a su población, del protagonismo, en relación con las políticas y actuaciones que se diseñen.

\section{4.- La responsabilidad social pública como política de empleo}

Desde un punto de vista técnico y como hemos expuesto, los poderes públicos asumen responsabilidades de diversa naturaleza -y no sólo a nivel político, legal o ético- que, además de incorporar los tradicionales parámetros de legalidad, eficiencia, eficacia y economía, persiguen un interés público y el bienestar social. Los objetivos del Estado de bienestar surgen inicialmente de la cobertura de necesidades económicas y sociales al hilo de los fallos del mercado y del propio crecimiento económico, pero las instituciones sociales buscan la eficiencia, la equidad y el desarrollo de una administración factible que incida en el aspecto social ${ }^{6}$ y no sólo en los aspectos económicos. El actual Estado de bienestar no se limita a la intervención estatal en la economía para mantener el pleno empleo 0 , al menos, garantizar un alto nivel de ocupación o la provisión pública de una serie de servicios sociales o medioambientales universales, incluyendo transferencias que cubran las necesidades humanas bási-

6.- También en el aspecto medioambiental, pero al ser este el que a nuestro juicio, es el más común - quizá por más fácil de cumplir tanto por las empresas como por las administraciones públicas - hemos decidido dejarlo como residual en este trabajo, salvo en lo relativo al empleo que pueda generar su aplicación. 
cas de los ciudadanos en una sociedad compleja y global. La responsabilidad en el ámbito público también conlleva el mantenimiento de un nivel mínimo de vida, entendido como no como caridad pública o filantropía para una minoría, sino como un problema de responsabilidad colectiva.

En la literatura, dos concepciones opuestas hacen referencia a los comportamientos que pueden adoptar los actores públicos, y más concretamente los gestores públicos. La primera deriva de la concepción weberiana del "estado benévolo", según la cual estos actores buscarían la defensa del interés general y la maximización de bienestar colectivo (Weber, 1919). La segunda, salida de la teoría de la elección pública (Buchanan y Tullock, 1962; Laffont, 2000), rechaza la hipótesis precedente, considerando que estos actores se comportan como agentes que buscan la maximización de su propia función de utilidad, bajo una red de presiones económicas y políticas. En el marco de un "estado imperfecto" (Guenerie, 2000), el argumento de esta función es ante todo el interés personal y no hay nada más personal que un empleo para mantener un nivel económico y de participación en la sociedad aceptable. Pero la aplicación de estas políticas no llega a la consecución de los fines que se le prevén en su diseño, porque, como hemos apuntado con anterioridad, se encuentran inmersas en una obsolescencia que las mantiene en un círculo vicioso de diseño que, después de 30 años, sigue sin tener resultados efectivos y eficaces.

No se trata tanto de rechazar esta hipótesis teórica evidente. Si algunos trabajos anteponen el compromiso de los dirigentes políticos en favor del interés general y subrayan su apego a los principios de universalidad, imparcialidad e integridad (Mazouz y Tardif, 2006) a través sobre todo de la puesta en marcha de acciones de RS a disposición del bien común (Caron y Charnonneau, 2008), otros son más escépticos. Se percibe, de este modo, en las acciones de la RS pública un medio de servir a su función de utilidad personal. Por ejemplo, estos actores pueden desarrollar acciones de RS con el fin de favorecer su enraizamiento en la perspectiva de una privatización futura de la administración pública (Labaronne y Gana-Oueslati, 2011). Con esto queremos hacer referencia a la afectación de los servicios públicos por unas corrientes liberalizadoras, amparadas en un impulso desde el derecho comunitario europeo, en el que el concepto de privatización adopta, o puede adoptar, tres acepciones que hacen referencia a distintos fenómenos, cuales son, por un lado, la utilización por la administración de personificaciones y procedimientos de derecho privado, por otro la transferencia al sector privado de una actividad o función pública o como una transferencia de la actividad comercial e industrial de la administración al sector privado (Carazo, 2011). Y en tal caso, ¿dónde situamos la responsabilidad pública en la generación de empleo imbricada en la RS?

Son varias las teorías que analizan los comportamientos de los gestores públicos 0 , si se quiere, los comportamientos de las propias administraciones públicas. La teoría de la gestión pone en valor el hecho de que los dirigentes de las empresas públicas o privadas no sean siempre oportunistas. Si la teoría de la agencia subraya el comportamiento individualista de los gestores y su voluntad de maximizar su propia función de utilidad, la teoría de la intendencia (Donalson y Davis, 1991) insiste en los comportamientos morales de los gestores. En esta prevalece la hipótesis de una convergencia de intereses entre agentes en razón de las satisfacciones morales que demuestran la bondad de la inten- 
dencia de los mismos. Estos tendrían por función de utilidad contribuir al desarrollo a largo plazo de la administración que dirigen puesta al servicio del interés general. El conjunto de estas teorías, expuestas de manera muy breve y sintética, nos puede dar una idea de que la convergencia de intereses siempre tendrá mejores resultados que la divergencia. Por aquello de "remar todos en una misma dirección".

\subsection{Las cláusulas de empleo en la contratación pública}

El volumen de contrataciones públicas tiene un peso presupuestario muy superior al de las partidas que cualquier administración dedique a políticas activas de empleo. Parece, por tanto, pertinente destinar parte de este presupuesto de contrataciones a fomentar el acceso a las mismas a colectivos con dificultades de inserción al mercado laboral, de forma complementaria a otras actuaciones.

Utilizamos de manera sinónima al de cláusulas de empleo, el término más extendido de cláusula sociolaboral -justificada esta sinonimia en las connotaciones de política social que tiene el empleoy la definimos como toda disposición incluida en un contrato o acuerdo comercial en virtud de la cual la parte prestadora del servicio o ejecutora de la obra asume, como condición de acceso o de ejecución, el compromiso de cumplir con determinados objetivos de política sociolaboral, como son la creación de más y mejor empleo y la garantía de mantenimiento de los derechos laborales y la igualdad de oportunidades (Molina, 2008).

La incorporación de las cláusulas sociales en la contratación pública como nuevos instrumentos que posibilitan políticas públicas de fomento del empleo, la igualdad de oportunidades y la lucha contra la exclusión social, fundamentalmente a nivel local, supone el uso de una herramienta innovadora que puede dar un nuevo impulso a las políticas de empleo y de inclusión social, a la inserción laboral de colectivos excluidos del mercado de trabajo como parte de las políticas sociales de lucha contra la exclusión.

La contratación pública se basa actualmente en unos criterios objetivos -condiciones técnicas y precio- y la aplicación de unos principios - libre concurrencia y publicidad-, no teniendo en cuenta otros principios más importantes de carácter ético, social y solidario, como el fomento del empleo de personas y colectivos desfavorecidos, la igualdad de oportunidades entre mujeres y hombres, el empleo de calidad y con derechos, la protección medioambiental, el comercio justo, en definitiva la compra ética y responsable.

Las medidas de política de empleo y de inclusión social en los últimos años no se renuevan y siguen apuntando únicamente a mejorar la "empleabilidad" y a remover ciertos obstáculos de acceso al mercado de trabajo, mediante incentivos a la contratación; pero no se cuestionan el modelo de crecimiento económico como principal factor causante de la exclusión. Seguimos teniendo mercados de trabajo excluyentes y discriminadores. Mediante la aplicación de las cláusulas socio-laborales se 
consigue, además de la realización de las obras o prestación de servicios, una rentabilidad social que supone una inversión que contribuye, por un lado, a disminuir el gasto público destinado a estos fines -programas sociales, rentas básicas, subsidios por desempleo o gastos sanitarios- y, por otro lado, a generar ingresos a la Hacienda Pública -IRPF, IVA y Seguridad Social-. El llamado "retorno social".

No siendo esta cuestión una cuestión novedosa en el ámbito de trabajo que nos movemos, sigue siendo una herramienta de política de empleo territorial poco desarrollada y utilizada por las Administraciones Locales, salvando, claro está, los municipios pioneros en la inclusión de cláusulas sociales, que durante más de una década han venido introduciendo en la contratación pública aspectos de política social, medioambiental o de comercio justo, y todo pese a las iniciales reticencias del empresariado previas a la entrada en vigor del Texto Refundido de la Ley de Contratos del Sector Público (TRLCSP) ${ }^{7}$ y la Directiva Europea 8 .

¿Dónde reside pues, la novedad de la reflexión en relación a la inclusión de estas cláusulas? Precisamente en el poco uso que de ellas se hace y en la necesidad de concienciación e introducción de las mismas en las Administraciones públicas como ámbito de política de empleo. Pero también en buscar nuevas formas de política de empleo más allá de los "escasamente útiles" incentivos a la contratación y más cercanos a la incentivación de la creación de empleo.

A continuación exponemos el reciente marco normativo y jurisprudencial en relación a los procesos de incorporación de aspectos sociales en la contratación pública y apuntamos algunos procedimientos de actuación de la administración en materia de cláusulas sociales, que ilustren la puesta en práctica de nuestros argumentos teóricos, así como buenas prácticas procedentes de otros países que ilustren nuestra argumentación.

\subsection{Las condiciones de legalidad: Marco normativo y jurisprudencial reciente}

Precisamente el TRLCSP de 2011 contempla varias posibilidades para tener en cuenta aspectos sociales en la contratación: como condiciones especiales de ejecución del contrato (art. 118); como criterio de valoración de las ofertas (at 150.1); preferencia en la adjudicación en igualdad de ofertas a empresas que tengan en su plantilla personas con discapacidad o en situación de exclusión social y con entidades sin ánimo de lucro y a entidades reconocidas como Organizaciones de Comercio Justo (DA 4); reserva de contratos para Centros Especiales de Empleo (DA 5a).

7.- Real Decreto Legislativo 3/2011, de 14 de noviembre por el que se aprueba el Texto Refundido de la Ley de Contratos del Sector Público (BOE de 16/11/2011).

8.- Directiva 2014/24/UE del Parlamento y el Consejo, de 26 de febrero de 2014, sobre contratación pública y por la que se deroga la Directiva 2004/18/CE (DOUE 28/03/2014). 
Al hilo de esta normativa, muchos Ayuntamientos y Comunidades Autónomas han publicado normas para incorporar en sus contratos diferentes tipos de consideraciones sociales: Avilés, Castellón, Pamplona, Córdoba, Valladolid; Diputaciones Forales de Guipúzcoa y Bizkaia; Generalitat de Cataluña; Junta de Castilla y León; Gobierno de Aragón; etc. Entre las normas autonómicas más recientes que abogan por la inclusión de consideraciones sociales en la contratación pública pueden verse la Ley 7/2014, de 13 de noviembre, de Garantía de los Derechos de las Personas con Discapacidad en Castilla-La Mancha (arts. 50, 51 y 51; el 51 se titula "Cláusulas de responsabilidad social en la contratación pública"); la Ley 10/2014, de 3 de diciembre, de accesibilidad de Galicia -su art. 40 incide en la importancia de los pliegos técnicos "instrumentos de control" para garantizar el cumplimiento de las medidas de accesibilidad para personas con discapacidad-; 0 el Convenio de colaboración entre el Consejo de Gobierno de la Junta de Extremadura y el Ministerio de Empleo y Seguridad Social para el fomento de la contratación pública responsable, de febrero de 2015.

Igualmente los órganos consultivos y los Tribunales se han pronunciado ampliamente sobre la legalidad de diferentes aspectos de política social en la contratación pública; por citar solo algunos pronunciamientos recientes: IJCCAE 14/2013; IJCCA de Aragón 1/2015, de 17 de marzo; IJCCA de Cataluña 18/2014, de 17 de diciembre; RTACRC 56/2015, de 20 de enero; RTACRC 891/2014, de 5 de diciembre; STSJ del País Vasco 617/2014, de 30 de diciembre de 2014, rec. 630/2014, que valida la citada Norma Foral 4/2013 de Gipuzkoa. Y también los OCEX recomiendan la inclusión en los pliegos de criterios sociales -Informe de 24 de octubre de 2014 del Consello de Contas de Galicia Contratación Administrativa 2010-2011-y reclaman el cumplimiento de las obligaciones que impone la Ley Orgánica 3/2007, de 22 de marzo, para la igualdad efectiva de mujeres y hombres (informes del Tribunal de Cuentas $n^{\circ} 1085$, de 26 de marzo de 2015 y n⿳0 1022, de 30 de enero de 2014). En todo caso, la exigencia de que los criterios sociales estén vinculados con el objeto del contrato es permanente cuando se alude a criterios de adjudicación (RTACR 891/2015), vinculación que nos parece también lógica cuando se trate de condiciones de ejecución -como exige expresamente el art. 200 del ALCSP-.

En el avance hacia una contratación social más responsable se han de mencionar: el Plan de acción de la estrategia española sobre discapacidad 2014-2020, aprobado por Acuerdo del Consejo de Ministros el día 12 de septiembre de 2014, cuyo objetivo operativo 4 es "Fomentar la contratación pública socialmente responsable, con una actuación precisa"; la Estrategia española de responsabilidad social de las empresas 2014-2020, (Acuerdo del Consejo de Ministros el 24 de octubre de 2014), que trata de armonizar y reforzar las distintas actuaciones que en relación con la Responsabilidad Social se están desarrollando, en los ámbitos público y privado, y alinear los compromisos de las empresas y de las Administraciones con la generación de empleo y la cohesión social; el Programa Nacional de Reformas 2014, que recoge los compromisos de reformas del Gobierno de España con la Comisión Europea, y asume muchas de las propuestas y recomendaciones presentadas por el Tercer Sector de Acción Social (páginas 96 y 97). Desde el ámbito privado, el Foro de la Contratación Pública Socialmente Responsable, plataforma impulsada por la Fundación ONCE y el Comité Español de Representantes de Personas con Discapacidad (CERMI), 
al que están adheridos algunos Ayuntamientos y grandes empresas, tiene como principal objetivo es favorecer la empleabilidad de las personas con discapacidad a través de la contratación pública (el Ayuntamiento de Valladolid se adhirió a este foro el día 14 de abril de 2015).

Pero del carácter voluntario de la inclusión de consideraciones sociales en la contratación del sector público, se están dando pasos hacia la obligatoriedad de tener en cuenta aspectos de tipo social en todos los contratos públicos, salvo que se acredite la incompatibilidad con el objeto del contrato de que se trate.

Algunas CCAA ya han regulado el carácter obligatorio de las cláusulas sociales. Así la Ley 2/2013, de 15 de mayo, de Igualdad de Oportunidades para las Personas con Discapacidad de Castilla y León, exige que "las Administraciones Públicas de Castilla y León, en el marco de la legislación de contratos del sector público, aplicarán un régimen de contratación pública socialmente responsable", requiriendo expresamente actuaciones concretas en su artículo 48.2 a la Administración autonómica, a Ayuntamientos y Diputaciones. En el mismo sentido, la Ley Foral Navarra 1/2015, de 22 de enero, por la que se modifica la Ley Foral 6/2006, de 9 de junio, de Contratos Públicos, para la introducción de cláusulas sociales en los pliegos de cláusulas administrativas con carácter obligatorio en los contratos del sector público de esa Comunidad. El Ayuntamiento de Valladolid ha hecho también regla general la incorporación de consideraciones sociales en todos sus contratos, en una Instrucción de Contratación adaptada a las nuevas Directivas y al ALCSP, aprobada el 17 de mayo de 2015.

La Directiva 2014/24/UE del Parlamento Europeo y del Consejo de 26 de febrero de 2014 sobre contratación pública, requiere a los Estados adoptar medidas efectivas para garantizar en la ejecución de los contratos el cumplimiento de los compromisos sociales legal y convencionalmente establecidos, en su artículo 18.2, precepto regula los principios básicos de la contratación pública, lo que denota la importancia que se confiere al tema. Además de este mandato general imperativo, se alude expresamente a los aspectos sociales en la definición del objeto de los contratos (art. 62); en los motivos de exclusión de contratistas (art. 57); como criterios de adjudicación (art. 67); y como condición de ejecución (art. 70).

La trasposición de las Directivas sobre contratación al ordenamiento jurídico español, está lógicamente presidida por la concepción "estratégica» de la contratación pública. La exposición de motivos del anteproyecto de Ley de Contratos del Sector Público (ALCSP en adelante, referido al texto publicado en marzo de 2015) señala expresamente que el sistema legal de contratación pública "trata de conseguir que se utilice la contratación pública como instrumento para implementar las políticas tanto europeas como nacionales en materia social, medioambiental, de innovación y desarrollo y promoción de las PYMES y todo ello, garantizando la eficiencia en el gasto público y respetando los principios de igualdad de trato, no discriminación, transparencia, proporcionalidad e integridad" (apartado III; el Anteproyecto de ley de sectores especiales utiliza las mismas palabras en el apartado II de su EM). Y la obligación que impone en el artículo 18 de la D. 2014/24 se recoge en el artículo 199 del ALCSP, que exige a los órganos de contratación adoptar las medidas para garantizar que en la eje- 
cución de los contratos los contratistas cumplen las obligaciones aplicables en materia social o laboral establecidas en las disposiciones nacionales e internacionales "que vinculen al Estado", sin remitir a la relación de convenios que recoge la Directiva, lo que la hace más general y abierta. En relación con esta obligatoriedad, la exposición de motivos del ALCSP, en su apartado V, precisa que "se impone al órgano de contratación la obligación" de introducir en los contratos públicos consideraciones de tipo social, medioambiental y de innovación y desarrollo, "pero se le deja en libertad para que pueda decidir si las incluye en cada contrato en concreto como criterio de adjudicación o como condición especial de ejecución".

El ALCSP, incorpora todas las consideraciones de tipo social que contempla el TRLCSP, e introduce importantes avances, además del citado artículo 199. El artículo 145 regula los criterios de adjudicación y amplía las previsiones del artículo 150 del TRLCSP, con una referencia expresa, además de a las "características sociales", "al suministro o a la utilización de productos basados en un comercio equitativo durante la ejecución del contrato"; además precisa los criterios para resolver empates que el TRLCSP regulaba en la DA $4^{a}$, incluyendo las el mayor número de iniciativas puestas en marcha por los licitadores afectados en el ámbito de la responsabilidad social corporativa (art. 145.10.d). El artículo 147 resuelve en sentido positivo una cuestión muy debatida, si las ofertas han de respetar los costes laborales de los convenios colectivos (IJCCAE 34/2001; RTACRC 56/2015; también la citada Ley Navarra 1/2015 exige el respeto a los costes derivados del convenio aboral sectorial que corresponda). El artículo 200 regula las condiciones especiales de ejecución, ampliando las previsiones del 118 del TRLCSP, con una referencia expresa al "comercio justo". En materia de subcontratación, se especifica que el contratista principal que asumirá la total responsabilidad de la ejecución del contrato frente a la Administración, "incluido el cumplimiento de las obligaciones en materia medioambiental, social o laboral a que se refiere el artículo 199" (art. 213). La DA 1ª , sobre contratación en el extranjero, exige que también en estos contratos se cumplan las normas de la Ley sobre obligaciones sociales. Y la DA $4{ }^{a}$ permite expresamente que también las CCAA y las EELL puedan reservar contratos para Centros Especiales de Empleo, las empresas de inserción o de los programas de empleo protegido (si bien parece rebajar del 70 al 30\% de los sean trabajadores "discapacitados en riesgo de exclusión social", terminología y porcentaje que no parecen adecuados a la normativa específica).

En definitiva, el ALCSP avanza firme y positivamente, en nuestra opinión, en la obligatoriedad de la inclusión de consideraciones sociales en los contratos públicos. Quizá podría incluir una referencia expresa en su artículo 145.1 a que la adjudicación haya de recaer siempre en la "oferta económica y social más ventajosa", como recoge el Programa Nacional de Reformas 2014 (pág. 96); e imponer que los criterios de desempate de las ofertas hayan de ser siempre de tipo social, y no con carácter potestativo que prevé el artículo 145.9. 


\subsection{El modelo de contratos reservados. ¿Acción positiva o discriminación?}

Una de las fórmulas que la legislación habilita para limitar la admisión de licitadores a determinadas empresas, consiste en aplicar la Disposición Adicional 5 del Real Decreto Ley 3/2011 sobre contratos reservados. Se trata de establecer unos porcentajes mínimos que no distorsionan la libre concurrencia y fomentan mercados inclusivos en el territorio. Actualmente los contratos reservados se establecen para fórmulas muy concretas del tercer sector -empresas de inserción (EI) y centros especiales de empleo (CEE)- pero quizá abrir esta fórmula a otras modalidades empresariales de este tercer sector o incluso a micro-empresas, que al fin y a la postre son las generadoras de empleo en los territorios, tendría una incidencia mayor en la creación de empleo.

Restringir a fórmulas de tan escasa presencia podría suponer una limitación al crecimiento e incluso incrementar las reticencias tanto de la propia administración que ofrece mercado, como a las empresas presentes en el espacio local. Esto no significa que no apoyemos la acción positiva a las El y a los CEE, de los que somos firmes defensores por todas sus características sociales, pero puesto que las actividades en las que estas entidades actúan son más limitados, la ampliación en otras actividades no competitivas con los espacios que estas ocupan y que pueden seguir estando "reservados", pueda generar una mayor capacidad de empleo.

Existen en España más de 200 empresas de inserción, que emplean a más de 4.000 personas en situación o riesgo de exclusión social, así como 1.897 Centros Especiales de Empleo, que contratan laboralmente a 54.200 personas con discapacidad, casi el $13 \%$ del total del empleo de personas con discapacidad.

La Directiva Comunitaria justifica en su Considerando 28 la importancia del empleo y especialmente el beneficio que producen determinadas empresas, y alude expresamente a las dificultades que tienen para competir en el mercado y la necesidad, por tanto de que las Administraciones Públicas les reserven un porcentaje de los contratos públicos. A su vez, la Comunicación Interpretativa de la Comisión sobre las posibilidades de incorporar criterios sociales en los contratos públicos (15 de octubre de 2001) se refiere a una reserva general para personas desempleadas, sin especificar un tipo u otro de empresas protegidas, siendo su única preocupación la de no discriminar a empresas de los países miembros de la UE.

No es una cuestión nueva, de ahí las voces que se alzan en contra de la reserva de los mercados por considerarla una fórmula discriminatoria para el resto del empresariado, pero bien gestionadas, informadas y justificadas, esas voces reticentes verían quizá una oportunidad más que una amenaza y probablemente como un incentivo de propio crecimiento. 
Para ilustrar esta reflexión no podemos dejar de hacer referencia a una Resolución reciente del Tribunal Administrativo de Contratación Pública de la Comunidad de Madrid ${ }^{9}$ que avala que el Consistorio premie en las licitaciones a aquellas empresas con mejores condiciones de trabajo para sus empleados. El Tribunal entiende que la legislación -tanto la nacional como la comunitaria-contempla que los contratos públicos exijan una serie de cláusulas sociales y premien de esta manera las mejores ofertas más allá del criterio único de coste-beneficio. Eso sí, el criterio económico debe pesar más que el resto, como así era en los pliegos objeto de recurso. El Tribunal sostiene que la cláusula que "pretende primar a las empresas que mejoren las condiciones de trabajo" de sus empleados, no puede considerarse "abusivo o gravoso". Además, el texto señala que en la actualidad existe "una tendencia legislativa y jurisprudencial favorable" en este sentido, y que administraciones y entidades de contratación están "implementando" sus políticas sociales con la inclusión de este tipo de cláusulas en los pliegos de los contratos públicos.

\subsection{Otras condiciones de adjudicación del contrato}

Cuando se decide establecer el criterio de oferta más ventajosa, deberá atenderse a condiciones directamente vinculadas al objeto del contrato, tales como la calidad, el precio, las características medioambientales, o vinculadas con la satisfacción de exigencias sociales que respondan a necesidades, definidas en las especificaciones del contrato propias de las categorías de población especialmente desfavorecidas a las que pertenezcan los usuarios o beneficiarios de las prestaciones a contratar. En este sentido, no hay oferta más ventajosa que la creación de empleo y las consecuencias que tiene en la economía local. La influencia del empleo en el precio de la oferta es mucho más que una reducción dineraria en el proyecto que se presenta.

En el caso de la introducción de consideraciones de tipo social con el fin de promover el empleo de personas con dificultades particulares de inserción en el mercado laboral, la cláusula forma parte del contrato y es una obligación inherente al mismo que los licitadores por el hecho de presentar su oferta se comprometen a cumplir en fase de ejecución. Es una condición positiva siempre que se lleve a cabo un intenso y exhaustivo control de estas exigencias de ejecución. La contratación de personas, aún para períodos vinculados a un proyecto específico, suele tener índices importantes de continuidad del empleo. 


\section{5.- El escenario europeo de responsabilidad social pública}

La adjudicación de contratos públicos por las autoridades de los Estados miembros ha de respetar los principios del Tratado de Funcionamiento de la Unión Europea (TFUE) y, en particular, la libre circulación de mercancías, la libertad de establecimiento y la libre prestación de servicios, así como los principios que se derivan de estos, tales como los de igualdad de trato, no discriminación, reconocimiento mutuo, proporcionalidad y transparencia. Ahora bien, para los contratos públicos por encima de determinado valor, deben elaborarse disposiciones que coordinen los procedimientos de contratación nacionales a fin de asegurar que estos principios tengan un efecto práctico y que la contratación pública se abra a la competencia.

La contratación pública desempeña un papel clave en la Estrategia Europa 2020, establecida en la Comunicación de la Comisión de 3 de marzo de 2010 titulada "Europa 2020, una estrategia para un crecimiento inteligente, sostenible e integrador" (EE2020), como uno de los instrumentos basados en el mercado que deben utilizarse para conseguir un crecimiento inteligente, sostenible e integrador, garantizando al mismo tiempo un uso más eficiente de los fondos públicos. Para la consecución de esta eficiencia, deben revisarse y modernizarse las normas vigentes sobre contratación pública adoptadas de conformidad con la Directiva 2004/17/CE del Parlamento Europeo y del Consejo y la Directiva 2004/18/CE del Parlamento Europeo y del Consejo, a fin de incrementar la eficiencia del gasto público, facilitando en particular la participación de las pequeñas y medianas empresas (PYME) en la contratación pública, y de permitir que los contratantes utilicen mejor la contratación pública en apoyo de objetivos sociales comunes. Asimismo, es preciso aclarar determinadas nociones y conceptos básicos para garantizar la seguridad jurídica e incorporar determinados aspectos de reiterada jurisprudencia del Tribunal de Justicia de la Unión Europea relativa a la contratación pública.

En Europa, sin embargo, el uso de cláusulas sociales en la contratación pública llegó a un punto de inflexión con la llamada sentencia Rüffert (C-346/06) del Tribunal de Justicia de la Unión Europea (TJUE), para el que el uso de este tipo de cláusulas son conformes con la legislación de la UE solamente cuando están respaldados por la Directiva Europea sobre desplazamiento de trabajadores (96/71 ( CE). En este sentido se aplicarán solo cuando se refieran al establecimiento del salario mínimo o con carácter universal en la aplicación de los respectivos convenios colectivos. Para todos los países incluidos en este estudio, la sentencia Rüffert introdujo algunos problemas significativos. $O$ bien ha llevado a la limitación en el alcance y el grado de compromiso de las cláusulas sociales o que ha creado grandes incertidumbres legales, en particular con respecto a la conformidad de la legislación de la UE con el Convenio 94 de la OIT, que ha sido ratificado por al menos diez estados miembros de la UE (Schulten, Alsos, Burgess, Pedersen, 2012). 
En Alemania, país afectado directamente por el asunto Rüffert, la mayoría de los estados federales no han tenido problemas en la inclusión de cláusulas sociales en sus normativas regionales sobre compra pública. La excepción la encontramos en el sector del transporte público, sin embargo, estas cláusulas sociales se introducen únicamente en los convenios colectivos de aplicación -y por lo general cubren sólo las categorías salariales más bajas- 0 en la cuantía del salario mínimo de contratación. En comparación con las leyes anteriores al caso Rüffert, que se referían a la prevalencia del nivel local en la aplicación de los convenios colectivos -incluyendo no sólo los salarios mínimos, sino a toda la escala salarial-, el alcance y la eficacia de las nuevas cláusulas sociales se encuentra bastante limitado.

A pesar de la sentencia Rüffert, Suiza continúa con la introducción de cláusulas sociales en la contratación pública que obligan a las empresas contratistas a pagar a sus trabajadores en los niveles salariales fijados en los convenios colectivos de ámbito local y a mantener las condiciones de trabajo establecidas en dichos convenios. Aunque Suiza no es miembro de la Unión Europea ni pertenece al Espacio Económico Europeo, debido a los acuerdos bilaterales concluidos con la UE tiene la obligación de poner en práctica, al menos en cierta medida, la normativa comunitaria sobre contratación pública. Esto provocó que después de la sentencia Rüffert algunas voces políticas exigían un cambio en la ley de contratación Suiza con el fin de restringir las cláusulas salariales de los convenios colectivos de aplicación. Si bien estos cambios aún no se han producido, sí han tenido como consecuencia algunas incertidumbres legales en relación a si el uso actual de las cláusulas sociales en la compra pública está en línea con los acuerdos bilaterales entre Suiza y la UE.

En los últimos años el Reino Unido ha visto crecer el número de iniciativas relacionadas con el establecimiento de un "salario digno" a nivel local que tienen como objetivo establecer un estándar local de cuantía salarial por encima del salario mínimo establecido en la norma nacional. Un instrumento importante para hacer cumplir tales niveles salariales ha sido la contratación pública. Sin embargo, todas las iniciativas puestas en marcha están basadas en una cuestión de voluntades y en la confianza en un compromiso político y moral (Barnard, 2011) Los intentos de la retribución de salarios dignos un criterio de adjudicación más vinculante, han sido rechazadas sin embargo en relación a la sentencia Rüffert. Como ha señalado la Oficina británica de Comercio, "este juicio significa que la imposición de una condición de contrato que requiera el pago del salario mínimo a los trabajadores con un contrato vinculado a una actuación de compra pública, supone un riesgo de acción legal contra el Reino Unido, sobre la base de que una restricción de la libre prestación de servicios "(OGC 2009: 4)10.

Por último, Dinamarca y Noruega, que han ratificado el Convenio 94 de la OIT, utilizan cláusulas sociales en la contratación pública referidas a la prevalencia de la aplicación de lo contenido en los 
convenios colectivos y no establecen cláusulas de aplicación universal. Mientras que en Dinamarca no existe posibilidad de declarar los convenios colectivos universalmente vinculantes, en Noruega, la limitación se establece para unos pocos sectores. Después de la sentencia Rüffert, en ambos países se han planteado dudas sobre si la regulación existente es conforme con la legislación comunitaria. Noruega ha sido acusado por el Órgano de Vigilancia (ESA) en relación a que determinadas cláusulas de los contratos no serían conformes con el principio de libre prestación de servicios según lo establecido en el artículo 36 del Acuerdo EEE. En respuesta a la misma, Noruega hizo algunas modificaciones a la ley de contratos en las que se aclara que los trabajadores vinculados con contratos públicos sólo están obligados a recibir las cuantías de salario mínimo acordadas en los convenios colectivos. Sin embargo, los convenios colectivos que no son universalmente aplicables siguen siendo una referencia para las cláusulas sociales. La misma cuestión se plantea para Dinamarca, donde la referencia se ha especificado en los convenios colectivos de ámbito nacional firmados por las partes (Dinamarca Ministerio de Trabajo 2012) ${ }^{11}$.

De acuerdo con el Consejo de la Unión Europea desde ahora "será posible incluir cláusulas que garanticen el cumplimiento de los convenios colectivos en cumplimiento de la legislación de la Unión en los contratos públicos". Aunque la expresión "cumplimiento de la legislación de la Unión", sin embargo, ya indica algunas limitaciones importantes de esta disposición. En este sentido el establecimiento del criterio de adjudicación o de determinadas condiciones de ejecución de contratos, relativas a los aspectos sociales del proceso de producción, deben aplicarse de conformidad con la Directiva 96/71 / CE, tal y como lo interpreta el TJUE y no debe elegirse 0 aplicarse de manera que discrimine directa o indirectamente a los operadores económicos de otros Estados miembros o de terceros países. En esta cuestión, el Consejo tiene de facto la potestad de limitar el uso de cláusulas sociales en la contratación pública al ámbito determinado por la sentencia Rüffert al tiempo que rechaza el alcance mucho más amplio establecido por el Convenio de la OIT 94. Esto es, sin embargo, contrario a lo que se ha exigido tanto por el Parlamento Europeo como por todo un elenco de organizaciones políticas de nivel europeo como de nivel nacional. Además, esta postura ignora por completo las necesidades que han surgido a partir de la utilización actual de las cláusulas sociales en relación con las cuestiones de empleo en diferentes estados europeos. 


\section{6.- Conclusiones}

La asunción de responsabilidades en materia de RS por parte de las entidades públicas tiene importantes consecuencias económicas y sociales; las principales, en el análisis que hemos realizado, se pueden concretar en la materia de creación de empleos directos e indirectos en los territorios donde se implanten estas medidas. Asimismo son fuentes indudables de lucha contra la pobreza y la exclusión social. Es por eso que tanto a nivel normativo como institucional, habrían de tomarse medidas en el ejercicio de acciones de clara incidencia en el crecimiento económico de los territorios a partir de las políticas de creación de empleo, justificadas en la obligación de las Administraciones Públicas en la responsabilidad social.

En este sentido, la introducción de cláusulas sociales en la contratación pública habría de ser un elemento prioritario en las políticas de crecimiento económico de los territorios, desarrolladas en toda su plenitud y con todas las consecuencias que en su implantación tienen, eliminadas las reticencias que inicialmente las limitaron, como puedan ser las referencias a la competencia desleal en el mercado.

Son, en este sentido, los espacios económicos de actuación y la necesaria creación de empleo en aquellos sectores más necesitados en función de las capacidades territoriales, el modelo de elección que cada administración pública implicada puede poner en marcha. Son por tanto políticas selectivas y adaptadas a cada uno de los espacios territoriales de influencia. Confiemos en las posibilidades de concienciación de las AAPP, cada una con sus propias responsabilidades, para implantar estas políticas sociales como modelo de crecimiento.

\section{Bibliografía}

ANCOS, H. (2011): "La responsabilidad social corporativa y sus actores: mitos y desafíos de la RSC". Primer seminario internacional de la Red interuniversitaria de RSE, Madrid, Instituto Complutense de Estudios Internacionales, Universidad Complutense de Madrid, 7-13.

BARNARD, C. (2011): "Procurement Law to Enforce Labour Standards". In: G. Davidov and B. Langille (eds.), The Idea of Labour Law, Oxford: University Press, 256-272.

BUCHANAN, J. \& TULLOCK, G. (1962): The Calculus of Consent: Logical Foundations of Constitutional Democracy, Ann Arbor: University of Michigan Press, 1962. 
CARAZO LIÉBANA, M.J. (2011): "Algunos apuntes sobre la constitucionalidad de la privatizacion de los servicios públicos", Cuadernos de Derecho Local (QDL), Fundación Democracia y Gobierno Local, 7, 51-62.

CARON, M.A. \& CHARBONNEAU, M. (2008): "Pour une traduction multiple de la responsabilité : engagement et action au pluriel". In: Eberhard, C. Traduire nos responsabilités planétaires : recomposer nos paysages juridiques, Bruylant, Brussels, 429-445.

CUETO CEDILLO, C. (2009): "Investigación, desarrollo, innovación y aplicación emprendedora $(I+D+i+e)$ de los modelos de transparencia y responsabilidad corporativa en los gobiernos y administraciones locales", Revista Análisis Local, 86, 7-28.

DANISH MINISTRY OF EMPLOYMENT (2012): Rapport fra Udvalget om modvirkning af social dumping.

DÍAZ, F., TORRES, I.T., MORALES, M. \& FARIAS, A. (2011): Evaluación de prácticas de responsabilidad social corporativa: comparación de las empresas españolas y chilenas, Fundación CarolinaCeALCl, Serie Avances de Investigación, 61, Madrid.

DONALSON, L. \& DAVIS, J.H. (1991): "Stewardship theory or agency theory: CEO governance and shareholder returns", Australian Journal of Management, 16.

DONALDSON, T. \& PRESTON, L.E. (1995): "The statehorder theory of the corporation: concepts, evidences and implications", The Accademy of management review, 20:1, 49-65.

ESTELA, O. (2012): "De la prestació de serveis al treball en xarxa: quines agencies per a quin desenvolupament local". En: Calvo et al. (coord.), Clústeres de empleo. Nuevas oportunidades de desarrollo del territorio, Germania, Alzira (Valencia), 53-66.

FERNÁNDEZ AMOR, J.A. (2008): "Reflexiones sobre el fomento público de la responsabilidad social empresarial relacionada con el medio ambiente", Nueva fiscalidad, 6, 9-57.

FERNÁNDEZ MORENO, M.V., PEÑA GARCÍA-PARDO, I. \& HERNÁNDEZ PERLINES, F. (2008): "Factores determinantes del éxito exportador. El papel de la estrategia exportadora en las cooperativas agrarias", CIRIEC-España, Revista de Economía Pública, Social y Cooperativa, 63, 39-64.

FREEMAN (1984): Strategic management : A stakeholder approach, Pitman.

GARCÍA DE ENTERRIA, E. (2003): "El principio de 'la responsabilidad de los poderes públicos' según el artículo 9.3 de la Constitución, y la responsabilidad patrimonial del estado legislador", Revista Española de Derecho Constitucional, Año 23, núm. 67, 15-48.

HEIDRICK \& STRUGGLES (2009): Corporate Governance Report 2009. Boards in turbulent times.

HEINCKE, M. (2005): "La Responsabilidad Social Empresarial: ¿una herramienta para el desarrollo sostenible en Colombia?", Revista Opera, 5:5, Universidad Externado de Colombia, Bogotá, 55-74.

HILL, C. \& JONES, T.M. (1992): "Stakeholder-Agency Theory", Journal of Management Studies, 29, 131-154. 
JONES, G.R. (1995): Organizational Theory. Text and cases, Addison-Wesley, Reading, Massachussets.

LABARONNE, D. \& GANA-OUESLATI, E. (2011): "Analyse comparative Maroc-Tunisie du cadre institutionnel de la RSE dans les PME", Management prospective, 43.

LAFFONT, J-J. (2000): Incentives and Political Economy, Clarendon Lectures in Economics, Oxford, UK New York: Oxford University Press.

MAZOUZ, B. \& TARDIF, M. (2006): "À propos de la performance : l'Arlésienne de le sphère publique", In: Proulx, D., Management des organisations publiques, Presses de l'Université de Québec.

MILLER-MILLESEN, J.L. (2003): "Understanding the Behaviour of non-profit boards of directors: a theory-based approach", Nonprofit and voluntary sector quarterly, 32, 521-547.

MOLINA NAVARRETE, C. (2008): "Relaciones laborales, política de empleo y compra pública socialmente responsable: las cláusulas sociales en la Ley 30/2007, de 30 de octubre, de Contratos del Sector Público", Revista de Trabajo y Seguridad Social, 302, 3-64.

MUSGRAVE, R.A. \& MUSGRAVE, P.B. (1973): Public Finance in Theory and Practice, New York: McGraw-Hill.

OGC (Office of Government Commerce) (2009): Procurement Policy Note-Quarterly Update, March.

PINO, A. "Modelo de Responsabilidad Social Organizacional en la Gestión Pública", Publicaciones Técnicas, 10.

PORTER, M.E. \& KRAMER, M.R. (2006): "Strategy and Society: the link between compeitive advantage and Corporate Social Responsability", Harvard Bussiness Review, 78-92.

RIVERA, J.M. (2010): RSC y Administraciones Públicas, Gestión de la RSC. Colección Sostenibilidad y Responsabilidad Social Corporativa, UNED-UJI, 193-240.

SCHULTEN, T., ALSOS, K., BURGESS, P. \& PEDERSEN, K. (2012): Pay and other social clauses in european public procurement, WSI.

VILLASANTE, T.R. (2011): "Juegos de contrastes y alternativas viables ante la RSC". En: Ancos, H., La responsabilidad social corporative y sus actors: mitos y desafíos de la RSC. Primer seminario internacional de la Red interuniversitaria de RSE, Madrid, Instituto Complutense de Estudios Internacionales, Universidad Complutense de Madrid.

WEBER, M. (1919): La política como vocación. En: http://www.bibliografiabasica.com.ar

YERA, T. \& PIN, J.R. (2010): La demanda social de la Responsabilidad Pública, Documento de Investigación DI-851, IESE-Universidad de Navarra. 